\title{
Swinburne University
}

\section{Julia Prendergast}

\section{A wake}

\section{Biographical note:}

Julia has a PhD in Writing and Literature. Julia's stories have been longlisted, shortlisted and/or published in TEXT journal, Lightship Anthology 2 (UK), Glimmer Train (US), the Séan Ó Faoláin Competition (IE), Review of Australian Fiction, Australian Book Review Elizabeth Jolley Prize and the Josephine Ulrick Prize. Her theoretical work has been published in TEXT journal, New Writing: The International Journal for the Practice and Theory of Creative Writing, Current Narratives (AU), and Testimony Witness Authority: The Politics and Poetics of Experience (UK). Julia's novel is forthcoming in 2017 (UWA Publishing). Julia teaches Writing and Literature at Swinburne University in Melbourne.

\section{Keywords:}

Creative writing - Death - Ideasthesia - Association - Metaphor 
Broadly speaking, wakes are parties or social gatherings held in connection with funerals. These sometimes involve keeping watch beside the corpse and behaving in a demonstrative way, either by lamenting or merry-making. This implication of unruliness is widespread. According to Brewer's Dictionary of Phrase and Fable (1978), the wake is 'a vigil celebrated with junketing and dancing'. The word primarily means, of course, to prevent someone from sleeping, to wake the person up, to disturb the person's slumber and make it impossible for him or her to slip back into it. The 'junketing and dancing; take place in order to wake the person up again. That is why, compared with ordinary social behavior, wakes stand out as wild and unrestrained: They have to be 'fit to wake the dead' (Encyclopedia of Death and Dying 2012).

It's my turn to talk. I have listened to Mum and Pelts fiercely, at our evening gatherings in front of the fire. My question has been the same since the beginning. I ask it, loud and clear: I want to know where Teddy is buried.

After a short silence, Mum says: I will show you. She stands, walking towards the laundry, slowly, like an old lady. Turning back, she takes my hand. She opens the laundry door, standing as still as stone on the concrete step.

Here? I say desperately. Is he here? It’s no more than a strangled whisper.

Mum takes a deep breath and steps out ten regular paces, counting them aloud as she heads towards the enormous old pine tree. When she gets to ten she slips off her shoe, leaving it on the grass to mark the spot. Then she walks over to the trunk of the enormous pine, stepping the paces out again from that side, heading back towards us, counting aloud. She arrives back at the same spot, slipping her foot back into the shoe. Here, she says. Teddy is buried here.

She crouches down and takes some grass and topsoil in her hand. Muttering, she rubs the grass and earth between her palms. I can't make out the words but there is a rhythm - it's like a spell but musical. She is singing. It's the bath song ...

I want to dig down. I say. I need to know that he is definitely there. My voice quivers but it's strong nevertheless. Tomorrow we dig, I say firmly.

Pelts heads out early for boutique beer. He buys champagne, white wine, and an exorbitant bottle of red. He decanters the red, placing the glass jug on the lounge room table. He fills the laundry tub with ice and booze.

Pelts gets busy preparing a range of food. He asks me to sample things as he goes, as if we're preparing for a party, as if we're expecting guests - salmon and dill focaccia, miniature toasts with caramelised onion and marinated fetta, a platter with olives and cheese, dips, marinated mushrooms.

In the crisp late morning, I put Mum out on a deck chair and get the Bocce set out for Grandad. He can play for hours, no rules - just the rhythmic thwack of coloured ball against coloured ball - he laughs delightedly on impact: an old man's laugh ghosted by 
boyish delight.

It's all quite civilised except that we're about to unearth a grave. As Pelts and I walk to the designated burial site, a fast-moving low-lying cloud passes overhead - the morning flickers grey and shadowy as if a light has short-circuited. The cloud passes momentarily and the sun is out again by the time our spades slice the earth.

We dig awhile, furiously. I stop to catch my breath and look over at Mum. I say: Mum? Are you sure it is okay with you? The digging. MUM?

Yes Shells.

If she'd said no I'm not sure what I'd have done. I am determined to dig. I need proof. Mum, you look pale. How do you feel?

She rubs her palms up and down her face. She says: Awake, Shells, I feel awake.

Well it is a 'wake', says Pelts. I'm not being facetious - is that the right word? I don't mean to be ... but it is Teddy's wake isn't it? I mean it probably is ...

We all glance at each other nervously and then I explode with laughter. I move to a different level of laughing. I'm laughing so hard that I'm crying. I wipe the tears away with my clay hands, painting streaky clay-stripes across my cheeks.

Pelts brings a tub with hot water, a face washer and soap, so we can wash our hands after we dig, so we have clean hands to eat. He stares at me as he washes his hands and then he is still, holding his hands together as if he were praying, clenched praying, fingers wrapped tightly around knuckles.

He takes a piece of soft clay and dunks it in the water tub, painting his cheeks like mine. I take the piece from Pelts and wander over to Mum, wiping the clay across her cheeks. Grandad won't be left out of the fun so we take care of him too. Grandad wants it everywhere, a full mask. We look like we're preparing for some kind of tribal ritual. We look ridiculous. As the clay dries, it stiffens our skin like plaster. Every smile feels like more than it is, every frown, so intentional.

Music? Says Pelts and I nod. He sets the stereo on the washing machine and puts the speakers through the laundry window. He chooses Celtic jigs and reels and pumps it up. It's a good choice, fast and dizzy, no words. We don't need too many words today.

Digging is thirsty work and nobody is interested in water or anything soft today. Soft drinks are unsuitable for waking the dead. At some point, Pelts refills the sink with beer and ice because it feels like thirty-three degrees, rather than twenty-three, digging in the sun. We knock back cold stubbies to quench our thirst: fast seamless sips to wash away the morbidity. We sip the beer, drinking fast and digging fast, in time with the music.

I mix a shandy for Grandad and resume the digging work. The music matches our momentum. I take on the rhythm of the reel, pounding the spade into the earth. My fingers dance against the green glass of the stubby as I take a long sip. Mum is jigging her knees slowly, up and down. 
I stop suddenly, breathing heavily. Go easy, I say, taking hold of Pelts' arm. We don't want to ... break him up.

He is in a fridge, says Mum.

What?

I put him in a fridge remember?

I rest my weight on the spade, puffing steadily. Sweat dribbles from my forehead down my clay cheeks, like muddy tears. I pause, drawing breath after breath. There is nothing to say about the fridge. We all stop because it's a dead moment.

I can't believe you dug this all alone, I say finally. I speak loudly, so that my voice will carry over the music, so that Mum can hear me loud and clear over the steadily growing mound of clay. I say: I can't believe there is so much clay. It looks like more than it was, now that we've interfered with it. ... How did you do it Mum? How did ...

There was nothing else I could do, she says, shrugging. Her voice breaks on else and the air becomes thick.

Shall I fire up the barbeque? says Pelts.

I wonder if it's okay to cook a barbeque when you're digging up a grave. It seems cannibalistic or something.

Pelts says: I have Greek lamb, butterfly lamb, and marinated chicken strips. ... We should eat or we'll be as pissed as maggots in no time.

Yes please, I say. Fire up the $B B Q$.

Pelts brings everything to the table: Greek salad and bread, roasted potato and sweet potato. We polish off our stubbies. He pours champagne and white wine, too many glasses for the three of us, and lemonade for Grandad. I turn the music down a little, just while we eat.

I have special red wine for tonight Annie girl, says Pelts. You'll love it.

It's after three before we are seated at the table. My shoes are slick, thick with clay. I'm dirty and exhausted from the digging. I look around the table and I feel good, proud of my ramshackle family. Pelts has the shock of wind in his hair and the hazy glaze of hard work in his eyes. Mum looks pale and sleepy, but serene. There's a touch of pink in her cheeks. Grandad is tucking into the lamb, his lips are glossy with the juices and his eyes sparkle with the pleasure of it.

Bon appétit, says Pelts, holding up his glass.

We clink our glasses together.

I say: If the ground was up to Mum's shoulders when she was standing in the hole - I mean, if the grave was as deep as she is tall, and there is a fridge in there too, then we must be getting close. ... Unless we have the wrong spot.

Pelts chews and swallows, pauses in the slick, thick reality that we are unearthing a grave, digging up the pent up, waking dead things.

You are very close, says Mum. There is no mistake about the place. 
Pelts serves everyone more lamb. He talks about the old days when Teddy and I were children, playing under the ancient pine tree. He says: I remember Teddy playing out here...

Grandad interrupts: $M e$ ?

No Grand, I say. Remember I had a brother. He had the same name as you; he was named after you. He died. He is buried in that hole. I'm making sure he is still there.

Oh, says Grandad. Where else could he be?

Nowhere, I say. But I need to make sure.

We get stuck into the digging again after lunch. I turn the music back on, the same CD, more reels and jigs, because the Irish know what they're on about; they know that happy and sad are not so different; they know that when things get tough, you need to party harder than ever. The music is not really civilised for gravedigging but it's highly appropriate too: the tempo, the wordless, firecracking, love-sweaty energy.

We've had a skin full of wine and beer but we keep on with the drinking and the digging. By the time Pelts' spade hits the fridge, metal on metal, an empty twang, there's not much sun left on the west side of the house - the wind has picked up and swung around. My spade clangs against the fridge a split second later, like a cymbal. I grab hold of Pelts' arm and that's the end of the digging.

I start weeping. I always thought crying and weeping were the same but they're not there's the mourning noise when we weep, like a donkey braying. I get down on my hands and knees in the hole and scoop the clay from the fridge by hand. Pelts follows my lead. It is warmer in the hole, because we're protected from the wind, but Mum and Grandad are feeling the cold. Pelts heads inside to get jumpers and coats.

The daylight is getting dingy now and it makes our clay faces look whiter. The spotlight from the laundry lights our faces. Our plaster masks glow like we're in a play.

Mum heads over to the edge of the hole and Pelts lowers her in. I'll light us a fire, he says, heading to the shed. He returns, carrying a fire drum toward the hole, placing it near Mum's chair. The drum is made from the old electric hot water system. Apparently it used to be in the roof. It looks like an enormous tin can. Pelts explains that when he renovated the bathroom, he put in a new gas system and he took the old drum out of the roof, splitting it lengthways and welding the rounded outer sides together. It makes a perfect, portable fire drum.

He fills the drum with paper and pinecones and loads of kindling. When he has it firing, he adds the ti-tree logs, the smaller pieces first. It smells like beach incense. The earthy smoke of ti-tree timber mixes with the perfume of the pinecones and the salty breath of the sea. He throws in the bushy branches, covered in ti-tree leaves. When the spray of leaves hits the flames they spark, like tiny white lights, like fireflies.

Pelts heads inside to get the decanter, brimming with red wine like black blood. He passes Mum and me a glass, down in the hole, explaining that it was bottled the same year that Teddy was born. 
I'm busy shifting the clay off the fridge door. I do it tenderly, kneeling down. I have the soap and water down there, and I'm cleaning the rusty old fridge door as if it were a tombstone, as if I'm trying to decipher the inscription, making sure I'm on the right grave. I pause and stand, taking a long sip of the velvety red wine. I drain the glass, very slowly, very steadily, breathing slowly through my nose.

I return to the work and, after a time, the old fridge is as clean as a whistle in its bed of clay. It looks like a coffin except that it is wider. The reality of the gravedigging is so very real now that we can see the fridge. Everyone is quiet. We will soon run out of daylight so Pelts gets the portable spotlight, and we shine it towards the hole. He plants a big battery lantern in the middle of the table, amongst the remnants of lunch. He pours more wine and throws extra logs on the fire. Lastly, he gets some mozzie coils and candles in glass holders, placing them around the hole.

Grandad has been playing Bocce all day, talking to himself, laughing wildly. Time for some warm clothes, old mate, says Pelts. Then we have cake. Your favourite chocolate. Pelts steadies Grandad as he steps into a pair of long pants, settling him in front of the fire with a piece of cake in each hand. Grandad watches the flames like television, mesmerised by the orange and white dance of firelight.

I say: I have to know he is in there. I know it's morbid and weird, but all of this is whack and I need to know for sure. GET MUM OUT, I say.

Pelts pulls her up.

Mum sits near the fire and Pelts brings a blanket for her legs and a scarf for her neck. Then he heads to the shed to get a crow bar. For a split second, I feel guilty, like we're doing something very wrong.

Pelts drops himself in beside me and I hitch a lift out because there's only room for one person if the fridge door is to be opened. I crouch next to the hole on my hands and knees, torso long, arms outstretched. I don't know why I'm reaching out like that, it doesn't make sense but I do it instinctively. I shiver but I'm not cold. I feel like a criminal.

Pelts heaves the crowbar back and forth. He is groaning and it goes on a long time. Grandad gets a bit distracted by the noise and I grab him another piece of cake and throw some ti-tree branches on the fire.

Pelts stops with the crowbar so I presume he’s in. He keeps the fridge door ajar, holding the crowbar steady, handing the top end of it to me. I hold on tight as he heaves himself out of the hole. Standing beside me, Pelts takes hold of the crowbar with one hand, helping me into the hole with the other. He reaches toward his feet and passes me one of the candles.

I'm in and out quickly. It's so fast after all that digging. I see a skull. I see ribs. I see a long leg bone. Skull, ribs, femur - candle-lit bones in a fridge coffin. It's proof enough of an alive-dead brother. Blatant bones in a rust bucket.

Pelts helps me out of the hole. He says: Shall I shut it now, Shells?

I nod. Mum nods too - well sort of, her head drops to her chest. 
We sit around the fire, keeping vigil. We're only a step or two from the hole. Pelts fills everyone's drinks. I stand, the warmth of the fire against my back, close to the hole. The others follow suit - without a word.

It's like a corroboree. I don't know anything about corroborees except I saw a show on the ABC: the fire and the music and the feeling that something momentous is going on between the living and the dead.

I can hear the waves, far-off, and the music, close-up. We stand around the hole. We don't move. No one is talking and time stands still - only the waves and the music to mark the undertow of time.

Grandad starts jigging to the music. Pelts moves the empty chairs back, away from the hole, and Mum starts dancing too, in her slow way - clapping behind the beat and swaying. Pelts grabs hold of Mum's forearm because she's unsteady. We've had a skin full of grog but Mum is so skinny - she’s very unsteady. We're all unsteady.

Our eyes glow like firefly sparks - our faces luminous. We pick up pace with the music, possessed with the wordless dance. We skip around the hole and the fire, waving our arms until we're sweaty and spent. We only stop because Grandad loses his footing and he nearly goes in the hole. That brings us back to the cold deadness of things. It puts an end to the dancing.

Pelts turns down the music. He tops up the drinks and the fire. We settle back to standing around the hole and I start talking.

We're not taking him out of the hole, I say. That's his resting place - it's part of his story. I want to put something here on the earth, to mark the spot, so that people can't just walk over him without even knowing.

Like a tombstone? asks Pelts.

No, I say.

Mum says: Teddy used to pick the fluffy-topped beach grass for me, lambs-tail, bunches of it. I had it everywhere around the house. He always brought me things, mostly the lambs-tail but shells and driftwood and sea grasses too. And all the little ti-tree blossoms, if it was the time for ti-tree snow, otherwise the browngreen leaves. He'd pick them up, one by one, patiently, all that tiny earth-coloured confetti. He'd bring it to me, cupped in his dear little hands, and I'd put it in bowls around the house, like offerings, as if the browngreen leaves had special powers and our luck would change. If we had the blossom we made wishes, sprinkling the papery white like magic dust...

Grandad says: The ti-tree leaves spark like stars, like wishing stars.

Pelts says: What about a ti-tree, then, to mark the spot?

No. Says Mum. Ti-trees need to be planted in groups because they are shallow-rooted. They survive because they stand in groups. They are safe in their numbers, like a family, safe in their crooked togetherness, protecting each other from the wind. They are topheavy and without each other the wind is too much - it unearths them, uproots them.

They drop their blossom quietly, like whispering, and their dead leaves - a breath of wind is enough to shake the deadness away and then they stand, still again, and green. 
The wind quiets and they go on greenly as if the dead leaving them were nothing but a breath of wind.

Their limbs are twisted, their trunks a network of veins: a plait of brown, bark veins. They sprout out at the top, top-heavy and unbalanced. They are silly trees, shallow rooted and top-heavy, but they are sea trees and I love them. They are part of this place.

I had no one to stand beside me except you, Shells, and you were too small to have planted your roots firmly. Life here is planted on a sand belt. Things give way and come up from under when you least expect it, no matter how strong you are.

Teddy was strong like a good, good man and I was stronger with him and I thought I was strong enough without him. I went on greenly, for you Shells. My roots were clawing at the sand. I was trying to keep hold but I was unsteady. Careering down dunes. I was out of control, running away from dead things, losing my hold. I was coming undone, unplaiting myself as I ran wildly with the wind, in all directions, and there was no one to keep me upright and we're on a sandy sand belt here, and things fall through your fingers and things come up from under when you least expect it.

I did my best Shells - it wasn't good enough for Teddy and it wasn't good enough for you. It's hard to stand beside yourself when your best is not good enough. My best wasn't good enough to see me stand beside my children, not good enough to see us stand together and keep hold ...

If you're not together with your people, like a family, the sand life wins and the wind takes hold and you're unwrung. Then there's nothing to hold you together because you're in the sand, and that's a shaky start if you're not linked together at the roots. Then the sand wins, not that the sand cares for winning, but the sand starts to shift between your roots if you can't hold on to your people. If the wind is at you and you're top-heavy with no family and shallow roots, you can't stand up anymore.

If you can't stand up you're not a tree, just firewood, or perhaps a home for the lizards and the spiders, or driftwood if you end up in the water. If you're lucky you end up in the wash.

In a way I wish they'd never found Teddy and he'd stayed in the sea, but then I wouldn't have been able to do the mother love touches and the last kisses ...

And I'm glad, Shells, that you know where he is, and we're back here, together now.... You're not a mother if you can't stand up with your roots. You're just dead wood.

We stand together around the hole, listening to Mum. She's talking to the fire and we listen. We move to the quiet music because the moving is like words, and we hold hands and move and speak to each other in that way.

I say: It has to be a wind vane, then, doesn't it Mum? There's nothing else that would be right.

Pelts says: There used to be a wind vane on the other side of the house. Near the kitchen window. But the North and South were broken and so I took it down. I could buy you another one. 
A wind vane, I say again. It's the right thing to put here when you think of everything together. It's the only thing to put here. ... We will plant the fluffy-topped beach grass all the way around the base at the bottom: a circle of lambs-tail around a big round concrete base for shells and driftwood and the ti-tree blossom. Mum?

Perfect Shells, says Mum - words strangled and gulping.

We sway together in the wordless dance.

I feel him in the wind near the water, I say.

He was a man for your Mum, says Pelts, crying wildly, a man before his time. He put the rest of us to shame.

I say: Grandad. Do you want to say something?

Grandad looks to the trees and the water - shivering grey branches like flailing arms silver-flecked darkness - the seductive wash - calling calling. Grandad lifts his nose, sniffing the salty breeze greedily.

I throw another bushy head of ti-tree on the fire and watch the sparks. We turn to Grandad and wait. I take Grandad's hands in both of mine. GRAND? Is there something you want to say?

Grandad looks at the hole. The mound of clay.

You have made a very big mess, he says. A shocking, muddy mess. You will have to clean it up, you know.

\section{Works cited}

Brewer, Rev E Cobham and Alix Gudefin 1978 The dictionary of phrase and fable New York: Avenel Encyclopedia of Death and Dying 2012, at http://www.deathreference.com/Vi-Z/Wake.html (accessed 30 March 2011) 


\section{Research statement}

\section{Research background}

Nikolić's concept of ideasthesia arises from the 'Ancient Greek words idea (for concept) and aesthesis (for sensation). Hence [...] the term ideasthesia [or] sensing concepts' (2016: 2). When we create narrative we generate ideas in sensory terms, as other. Ideasthesia takes an interest in the dynamics of the conversion process, from idea to story: what modes of poeisis are involved?

\section{Research contribution}

'A wake' is a story about the unearthing of a grave. It depicts an overdue wake. An impoverished mother had buried her son in the back garden many years before: his coffin a defunct fridge. The author's experience of ideasthesia provides a means for understanding writing process: a way of deconstructing how writers sense concepts (ideas) in metaphorical, associative and sensory ways. On a meta-level, ideasthesia takes an interest in the neurological processes involved in the generation of these images. Why are 'certain abilities [...] deliberately inhibited from conscious awareness' (Snyder 2009: 1)? Why do certain psychological conditions involve 'privileged access to lower level, less processed information' (Snyder 2009: 1)?

\section{Research significance}

'A wake' represents work towards the manuscript: 'The Earth Does Not Get fat'. Individual chapters from this manuscript have been longlisted, shortlisted and published in venues including in TEXT (AU), the Lightship Anthology 2 (UK), Glimmer Train (US), Review of Australian Fiction, Josephine Ulrick Prize (AU) and Ink Tears International Short Story Prize (UK).

\section{Works cited}

Nikolić, D 2016 'Ideasthesia and art', at http://www.danko-nikolic.com/wpcontent/uploads/2016/02/Ideasthesia-and-art.pdf (accessed 1 May 2017)

Snyder, A 2009 'Explaining and inducing savant skills: privileged access to lower level, less processed information’ Philosophical Transactions of the Royal Society 12 April, at http://rstb.royalsocietypublishing.org/content/364/1522/1399.full (accessed 1 May 2017) 